\title{
Electrochemical and Theoretical Study of Imidazole Derivative as Effective Corrosion Inhibitor for Aluminium
}

\author{
Jinchang Wang ${ }^{1,3}$, Ambrish Singh ${ }^{1,2, *}$, Mohd Talha ${ }^{1,2,}$, Xi Luo ${ }^{3}$, Xuefeng Deng ${ }^{3}$, Yuanhua Lin ${ }^{1,2,4^{*}}$ \\ ${ }^{1}$ School of Materials Science and Engineering, Southwest Petroleum University, Chengdu-610500, \\ Sichuan, China. \\ ${ }^{2}$ State Key Laboratory of Oil and Gas Reservoir Geology and Exploitation, Southwest Petroleum \\ University, Chengdu, Sichuan 610500, China \\ ${ }^{3}$ North China Oil and Gas Branch Company of SINOPEC, Zhengzhou, Henan 450006, China \\ ${ }^{4}$ CNPC Key Lab for Tubular Goods Engineering (Southwest Petroleum University), Chengdu, \\ Sichuan 610500, China \\ *E-mail: yhlin28@ 163.com; vishisingh4uall@gmail.com
}

doi: $10.20964 / 2018.12 .44$

Received: 8 February 2018 / Accepted: 28 March 2018 / Published: 5 November 2018

The corrosion inhibition performance of 2-styryl-1,8-dihydro-1,3,8-triaza-cyclopentaindene (IIZ) on Aluminium in $1 \mathrm{M} \mathrm{HCl}$ was investigated by electrochemical impedance spectroscopy (EIS), Potentiodynamic polarization, scanning electron microscopy (SEM), atomic force microscopy (AFM), and quantum chemical techniques. Potentiodynamic polarization study confirmed that IIZ is mixed type inhibitor with cathodic predominance. SEM and AFM confirm the formation of an adsorption film on the aluminium surface. Quantum chemical study reveals that protonated IIZ interacts more than neutral IIZ. The theoretical data obtained are in agreement with experimental results.

Keywords: Aluminium; Imidazole derivative, Corrosion; Electrochemical; AFM

\section{$\underline{\text { FULL TEXT }}$}

(C) 2018 The Authors. Published by ESG (www.electrochemsci.org). This article is an open access article distributed under the terms and conditions of the Creative Commons Attribution license (http://creativecommons.org/licenses/by/4.0/). 